\title{
SECAGEM DE SEMENTES DE MILHO EM ESPIGA, EM FUNÇÃO DAALTURADA CAMADA E FLUXO DE AR ${ }^{1}$
}

\author{
ELETISANDADAS NEVES ${ }^{2}$, SILMAR TEICHERT PESKE ${ }^{3,5}$, FRANCISCOAMARAL VILLELA ${ }^{4,5}$, \\ LEOPOLDOBAUDET ${ }^{3,5}$, WOLMER BRODPERES 6
}

\begin{abstract}
RESUMO - Os objetivos do presente trabalho foram determinar a velocidade de secagem em função do fluxo de ar e seu efeito na qualidade de sementes de milho. Foram utilizadas sementes de milho em espiga com umidade inicial de $30 \%$ secas, em quatro protótipos de secador de fundo perfurado, com diâmetro de 0,92m, altura de 1,0m e ventilador axial, com cilindros de altura 2,0m instalados internamente. Utilizaram-se fluxos de ar de 5, $10 \mathrm{e} 15 \mathrm{~m}^{3} \cdot \mathrm{min}^{-1} \cdot \mathrm{t}^{-1}$ e aquecimento do ar de $30^{\circ} \mathrm{C}$, o que proporcionou uma UR entre 40 e $70 \%$. As avaliações foram realizadas aos zero, seis e 12 meses de armazenamento, determinando-se a umidade das sementes durante a secagem, a percentagem de sementes fissuradas, a germinação e o vigor, pelos testes de envelhecimento acelerado, frio sem solo e emergência de plântulas em campo. Os resultados mostraram que a secagem estacionária, empregando ar com umidade relativa entre 40 e $70 \%$, não ocasiona fissuras às sementes de milho em espiga. A velocidade mínima de secagem de milho em espiga, com grau de umidade superior a $25 \%$, deve ser de 0,2 pontos percentuais por hora. O emprego de ar de secagem com umidade relativa entre 40 e 70\% determina um gradiente máximo de umidade de dois pontos percentuais no final da secagem, numa camada de $1,50 \mathrm{~m}$ de sementes de milho em espiga. A velocidade média de avanço da secagem de sementes de milho em espiga é afetada de forma não diretamente proporcional pelo fluxo de ar.
\end{abstract}

Termos para indexação: Zea mays, frente de secagem, qualidade de sementes.

\section{SEED DRYING OF CORN EARS AS AFFECTED BY LAYER DEPTH AND AIR FLOW}

\begin{abstract}
The objective of this study was to evaluate the stationary drying process of corn seeds on the ear at $30 \%$ moisture content dried in four perfurated floor prototypes with $0.92 \mathrm{~m}$ diameter, $1.0 \mathrm{~m}$ height and axial fan and internal tubes $2.00 \mathrm{~m}$ high. Air flows of 5.15 and $20 \mathrm{~m}^{3} \cdot \mathrm{min}^{-1} \cdot \mathrm{t}^{-1}$ were used with air heated to $30^{\circ} \mathrm{C}$ providing RH from 40 to $70 \%$. Evaluations were made after zero, six and 12 months of storage, determining seed moisture content during drying, proportion of internal breakage in seeds, standard germination, accelerating ageing, cold test without soil and field emergency. Results showed that stationary drying with 40 to $70 \%$ RH did not cause internally broken kernels of hybrid seed corn on the ear that were not affected even at the maximum air flow, nearest to the perfurated floor and to round seeds that are more susceptible to breakage. On the other hand, physiological quality was affected by air flows below $20 \mathrm{~m}^{3} \cdot \mathrm{min}^{-1} \cdot \mathrm{t}^{-1}$, as detected by cold germination after one year of storage. Maximum drying rate must be $0.18 \%$ /hour with seed moisture above $25 \%$; therefore, drying at 40 to $70 \% \mathrm{RH}$, the seed moisture gradient is $2 \%$ /hour up to $1.50 \mathrm{~m}$ seed layer height at the end of drying. Average drying front speed is not directly affected by air flow.
\end{abstract}

Index terms: Zea mays, drying front, seed quality.

\footnotetext{
${ }^{1}$ Submetido em 15/08/2004. Aceito para publicação em 01/04/2005. Parte da Tese de Doutorado defendida pelo primeiro autor.

${ }^{2}$ Eng. Agrícola, Dr., Bolsista Recém Doutor /CNPq, UFMT/FAMV, Av. Fernando Corrêa da Costa, S/N, Coxipó, CEP: 78.060-900, Cuiabá, MT. eletineves@hotmail.com
}

\footnotetext{
${ }^{3}$ Eng. Agrônomo, Ph.D., Prof. Titular, UfPEL/FAEM, Cx. Postal 354, Pelotas, RS, CEP:96001-970. peske@ufpel.edu.br

${ }^{4}$ Eng. Agrícola, Dr., Prof. Adjunto., UFPEL/IFM, Cx. Postal 354, Pelotas, RS, CEP:96001-970. francisco.villela@ufpel.edu.br.

${ }^{5}$ Bolsista de produtividade em pesquisa do CNPq.

${ }^{6}$ Eng. Agrícola, Dr., Prof. Adjunto, UFPEL/FEA.
} 


\section{INTRODUÇÃO}

A secagem de milho em espigas ocorre em secadores estacionários, os quais devem ser corretamente operados, no intuito de evitar a secagem excessiva das camadas inferiores e permitir que a camada superior seque de maneira suficientemente rápida para que não ocorra redução na qualidade das sementes. Desse modo, algumas precauções são necessárias quanto aos fatores que possam influenciar a operação de secagem, tais como o fluxo de ar, temperatura e altura da camada de espigas (Villela e Peske, 2003).

O fluxo de ar é o fator mais importante, principalmente, na secagem em baixa temperatura ou com ar natural porque quanto maior a quantidade de ar forçado que passar pela massa, mais rapidamente à frente de secagem se desloca, diminuindo o tempo de secagem e tornando o processo mais seguro (Queiroz e Pereira, 1987).

O fluxo de ar deve ser suficiente para não se tornar saturado antes de sair da massa de sementes, podendo ser elevado até que seja capaz de absorver toda a água evaporada das sementes. A partir desse ponto, a movimentação da água, do interior para a superfície das sementes, torna-se o principal fator a influenciar o tempo de secagem. Particularmente na secagem com ar aquecido, fluxos inferiores a $6 \mathrm{~m}^{3} \cdot \mathrm{min}^{-1} \cdot \mathrm{t}^{-1}$ podem prolongar excessivamente o tempo de secagem, enquanto que acima de $20 \mathrm{~m}^{3} \cdot \mathrm{min}^{-1} \cdot \mathrm{t}^{-1}$, podem tornar o processo antieconômico (Villela e Peske, 2003).

Resultados recentes com secador estacionário de insuflação radial de ar indicaram velocidades de secagem entre 0,20 e 0,52 pontos percentuais de água por hora, em sementes de milho debulhado e em nove horas de secagem, dependendo do fluxo e da temperatura do ar empregado na secagem, em equipamento com espessura da massa de $0,60 \mathrm{~m}$ (Baudet et al., 1999).

Referindo-se à secagem de milho em espiga empregando temperatura do ar de $40^{\circ} \mathrm{C}$, Herter e Burris (1989) destacaram a ausência de efeito negativo da secagem excessiva na qualidade das sementes.

O fluxo e a temperatura do ar insuflado, apesar de serem destacados nas pesquisas como relacionados aos danos fisiológicos provocados às sementes durante a secagem estacionária (Carvalho, 1994), não têm suas interações perfeitamente conhecidas.

Em estudo sobre as conseqüências do retardamento do início da operação de secagem de milho em espiga, cultivar BR 3123, com teor inicial de água de 32\% e sob condições ambientes, Scaranarci et al. (1997) concluíram que o retardamento, de até 120 horas, não promoveu efeitos prejudiciais à qualidade fisiológica das sementes armazenadas por seis meses.

Na secagem de sementes de três linhagens de milho em espiga, em secador estacionário, empregando temperaturas do ar de secagem de 35; 40; 45 e $50^{\circ} \mathrm{C}$, Navratil e Burris (1984) verificaram que apenas as temperaturas de 45 e $50^{\circ} \mathrm{C}$ afetaram, de forma adversa, a germinação e o vigor das sementes, sendo o desenvolvimento radicular das plântulas mais suscetível do que o desenvolvimento da parte aérea.

Em trabalho realizado com milho em espiga, para avaliação de seis híbridos, utilizando protótipos de secadores estacionários e combinações de temperatura de 35-40; 40 -

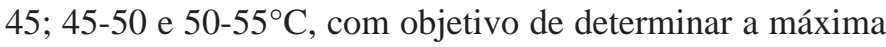
temperatura do ar de secagem que as sementes poderiam suportar, Peske e Lilge (1998) concluíram que se pode utilizar temperatura do ar de até $45^{\circ} \mathrm{C}$ na secagem de sementes de milho em espiga, com umidade inicial entre $30-40 \%$, sem afetar negativamente a qualidade fisiológica das sementes.

O fator determinante na qualidade final das sementes é o grau de umidade verificado após a maturidade fisiológica e que determinará seu potencial de armazenamento. A longevidade das sementes está diretamente relacionada ao grau de umidade de armazenamento das sementes (Chai, 1998; Hu et al., 1998; Walter e Engels, 1998). Resultados de pesquisas indicam que a máxima qualidade das sementes durante o armazenamento, em temperatura ambiente, pode ser mantida somente através de um adequado controle do grau de umidade. O armazenamento de sementes com alto grau de umidade sempre resulta na redução da percentagem de germinação, sendo o grau de umidade ideal variável entre as espécies. Assim, se para sementes de soja, $13 \%$ é marginal, para o armazenamento de sementes de milho é o grau de umidade recomendado (Baudet, 2003).

Considerando que a secagem é uma operação na qual a qualidade da semente pode ser afetada, os objetivos do presente trabalho foram determinar a velocidade de secagem em função do fluxo de ar e seu efeito na qualidade física e fisiológica das sementes de milho em espiga, com alto grau de umidade.

\section{MATERIALE MÉTODOS}

A presente pesquisa foi conduzida nos Laboratórios Didático de Análise de Sementes (LDAS) e de Produção de Sementes e no Campo Didático do Departamento de Fitotecnia, Faculdade de Agronomia “Eliseu Maciel”, Universidade 
Federal de Pelotas. Foi utilizado um lote de $768 \mathrm{~kg}$ de sementes de milho (Zea mays L.) em espiga, híbrido triplo Pioneer 3027, com grau inicial de umidade de 30\%, produzido pela empresa sementes Pioneer, Unidade de Santa Cruz do Sul, RS.

Após a colheita, as espigas foram transportadas para o Laboratório de Produção de Sementes, onde se procedeu o despalhamento manual, a remoção das espigas enfermas e a operação de secagem. Após a secagem, foi realizada manualmente a debulha das sementes, para obtenção das amostras para avaliação da qualidade. Antes de realizar a secagem, foi determinado o grau inicial de umidade das sementes, pelo método da estufa a $105 \pm 3^{\circ} \mathrm{C}$ (Brasil, 1992).

Na secagem das espigas foram utilizados quatro protótipos de secador estacionário, da marca Vitória, de fundo falso perfurado, com diâmetro de 0,92m, altura de 1,00m e ventilador axial com motor de $1 / 6 \mathrm{cv}, 1680 \mathrm{rpm}$ e $60 \mathrm{~Hz}$. No interior de cada um dos protótipos, foram colocados tubos de chapa metálica com 0,3m de diâmetro e 2,00m de altura, com cinco pontos de amostragem distribuídos verticalmente, eqüidistantes entre si em $0,25 \mathrm{~m}$, sendo o primeiro situado a $0,5 \mathrm{~m}$ da base do secador e o último a $0,5 \mathrm{~m}$ do topo (Figura 1). Os tubos foram completamente carregados com as espigas. Nos pontos de amostragem foram colocados termômetros analógicos para a determinação das temperaturas de secagem na massa de sementes.

A secagem foi realizada até o momento que as sementes do topo da camada alcançaram grau de umidade de $13 \%$.

Foi empregada temperatura constante de $30 \pm 1^{\circ} \mathrm{C}$, em cada protótipo. O aquecimento do ar foi obtido por meio de resistências elétricas instaladas no aeroduto, conectado ao plenum de cada secador. A temperatura do ar de secagem foi controlada na base da câmara dos secadores através de um termostato.

O fluxo de ar foi obtido utilizando um conjunto motorventilador axial, para insuflar o ar através da camada de milho em espiga. Fluxos de ar iguais a 5; 10; 15 e $20 \mathrm{~m}^{3} \cdot \mathrm{min}^{-1} \cdot \mathrm{t}^{-1}$ foram obtidos por meio de um mecanismo regulador de controle de vazão de ar. A partir da área, velocidade de entrada do ar e peso volumétrico do milho em espiga (450 kg. $\left.{ }^{-3}\right)$, calculou-se os fluxos de ar em cada protótipo. As velocidades do ar foram determinadas através de um termoanemômetro Hot Wire Anemometer, marca LT Lutron, modelo AM4204.

Para monitorar o avanço da frente de secagem, amostras foram retiradas nas diferentes alturas da camada de sementes no tubo do secador, para determinação do grau de umidade, a cada oito horas, nos cinco pontos correspondentes às alturas: $\mathrm{H}_{1}=0,50 \mathrm{~m} ; \mathrm{H}_{2}=0,75 \mathrm{~m} ; \mathrm{H}_{3}=1,00 \mathrm{~m} ; \mathrm{H}_{4}=1,25 \mathrm{~m}$ e $\mathrm{H}_{5}=$ 1,50m. Foi incluída mais uma altura $\mathrm{H}_{0}=0 \mathrm{~m}$, posição mais próxima à entrada do ar de secagem, junto ao fundo falso perfurado.

O monitoramento do grau de umidade das sementes durante a secagem foi realizado pelo método da estufa a 105 $\pm 3^{\circ} \mathrm{C}$, por 24 horas, conforme as Regras para Análise de Sementes - RAS (Brasil, 1992). Concomitantemente, foi realizada a determinação da umidade relativa do ar e da temperatura ambiental, através de um termohigrógrafo, instalado nas imediações dos pontos de coleta do ar pelos ventiladores, durante todo o período de secagem. Com esses dados, obtiveram-se os valores de umidade relativa (UR) do ar de secagem e UR e temperatura ambientais, cujos perfis são apresentados na Figura 2.

Após a secagem, as sementes foram armazenadas em embalagem de papel, em condições ambientais não controladas por um período de doze meses, com a realização dos testes de avaliação da qualidade fisiológica das sementes a zero, seis e doze meses.

Avaliação visual dos danos (fissuras) nas sementes - utilizando-se as amostras das diferentes alturas, incluindo a altura zero (junto ao fundo falso do secador). As sementes foram, inicialmente, classificadas por meio de peneira de furos oblongos, com dimensão de 6,5x25mm, em planas e redondas. A seguir, foram divididas em duas repetições de 100 sementes, para verificação de possíveis danos. A avaliação foi realizada em bancada com fundo branco e por meio de lupa, aumento de 10X, obtendo-se a percentagem de sementes com danos (fissuras).

Teste de germinação - conduzido de acordo com as RAS (Brasil, 1992), exceto pelo número de sementes adotado que foi de 200, distribuído em quatro amostras iguais.

Teste de envelhecimento acelerado - conforme metodologia descrita por Marcos Filho et al. (1987), com exceção do período de exposição. As caixas, contendo 40mL de água destilada, foram mantidas em estufa regulada à temperatura de $42^{\circ} \mathrm{C}$, onde permaneceram por 96 horas.

Teste de frio sem solo - As sementes foram semeadas de forma similar às submetidas ao teste de germinação (Loeffler et al., 1985). A seguir, os rolos foram colocados em sacos plásticos e mantidos, durante sete dias, em câmara regulada a $10^{\circ} \mathrm{C}$. Após esse período, os rolos foram levados para germinador a $25^{\circ} \mathrm{C}$, onde permaneceram mais sete dias. Decorrido este período, foi realizada a contagem e os resultados expressos em percentagem de plântulas normais.

Teste de emergência de plântulas em campo executado conforme metodologia descrita por Popinigis 

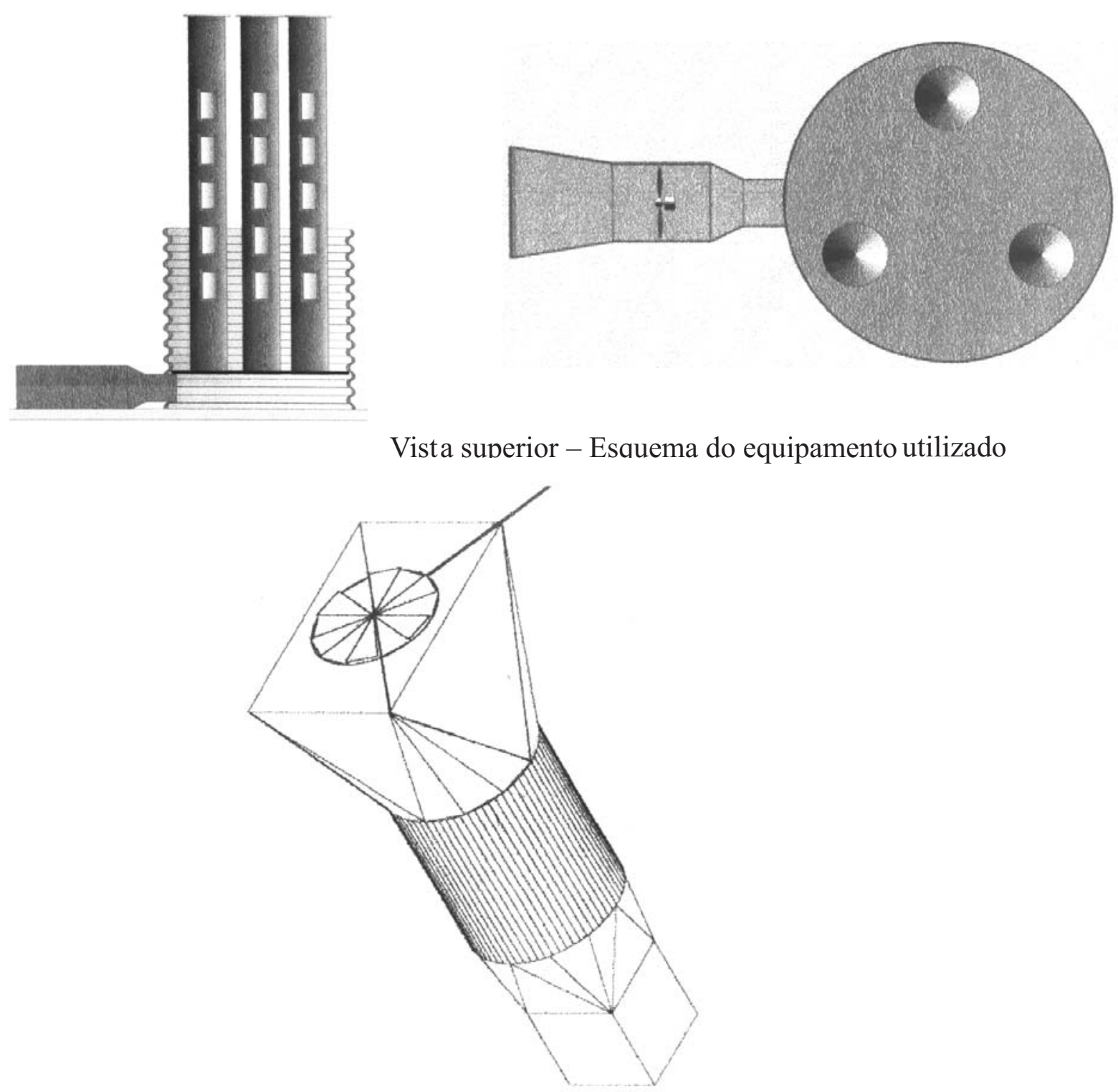

Detalhe tridimensional do regulador de vazão

FIGURA 1. Esquema do equipamento utilizado na secagem das sementes de milho em espiga.

(1985). As condições ambientais no período de realização do teste foram temperaturas mínima de $10,4^{\circ} \mathrm{C}$ e máxima de $32,2^{\circ} \mathrm{C}$, umidade relativa do ar de $83,5 \%$ e precipitação pluvial de $129 \mathrm{~mm}$. Foram utilizadas 200 sementes, distribuídas em quatro amostras de 50 sementes para cada repetição. Na semeadura foram utilizadas distâncias entre as sementes na linha e entre as linhas de dois e oito centímetros, respectivamente e profundidade de semeadura de três centímetros. A contagem foi realizada no décimo quarto dia após a semeadura e os resultados expressos em percentagem de plântulas emergidas.

As análises estatísticas foram executadas pelo Sistema 


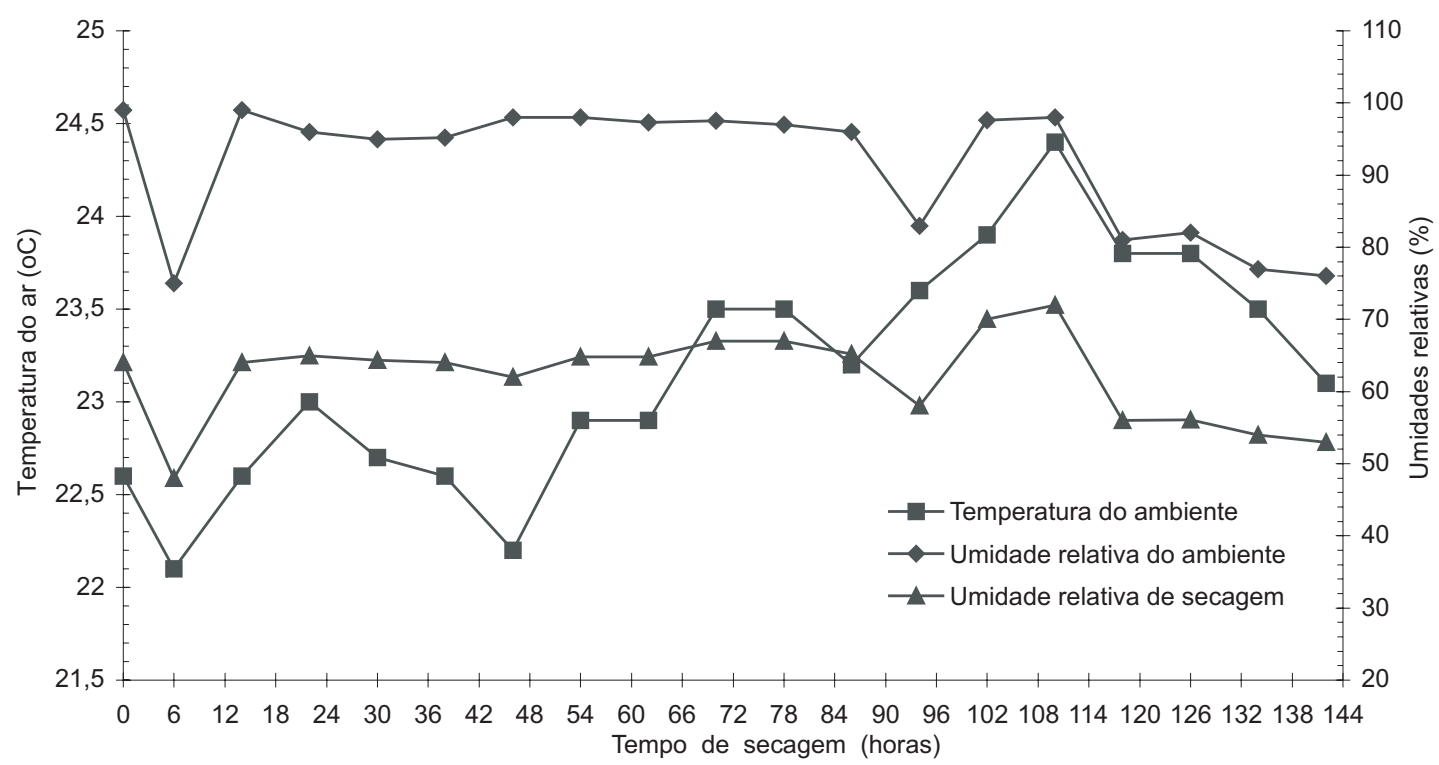

FIGURA 2. Perfis da umidade relativa do ar de secagem e da umidade relativa e temperatura do ar ambiente, durante o período de secagem de sementes de milho em espiga.

de Análise Estatística para Microcomputadores "SANEST" (Zonta e Machado, 1984). Para os dados de grau de umidade obtidos no monitoramento durante a secagem, com o objetivo de avaliar o efeito do fluxo de ar e da altura da camada de sementes sobre o avanço da frente de secagem, foi utilizado o delineamento experimental inteiramente casualizado, em esquema fatorial $4 \times 6$ (quatro fluxos de ar e seis alturas), com três repetições.

Os dados das variáveis obtidas para avaliação da qualidade fisiológica das sementes (germinação, frio sem solo, envelhecimento acelerado e emergência de plântulas em campo) foram previamente transformados em arco-seno, para análise de variância. Os efeitos de tratamentos na qualidade fisiológica foram comparados pelo teste de Duncan, em nível de probabilidade de $5 \%$. As curvas de secagem foram obtidas através de análise de regressão polinomial para o fator tempo de secagem, após a análise de variância.

\section{RESULTADOS E DISCUSSÃO}

Durante a secagem das sementes de milho em espiga, a umidade relativa (UR) do ar de secagem variou de 38 e $68 \%$ (Figura 2), considerado próximo ao intervalo de 40 a 70\%, recomendado por Villela e Peske (2003) para a secagem estacionária.

No presente trabalho, as sementes de milho não foram afetadas quanto às fissuras pela operação de secagem, resultado constatado em todos tratamentos, tanto para as sementes redondas como para as de forma plana. Todas as amostras apresentaram percentagem de fissura inferior a 1\%, inclusive para as redondas, que são mais suscetíveis, e para as amostras retiradas da altura de zero e $0,50 \mathrm{~m}$ no secador, com fluxo de ar de $20 \mathrm{~m}^{3} \cdot \mathrm{min}^{-1} \cdot \mathrm{t}^{-1}$, consideradas por Gunasekaran et al. (1985) e Peterson et al. (1995) como condições drásticas de secagem por sua rapidez . Isto significa que as condições operacionais de secagem utilizadas foram ajustadas adequadamente, minimizando assim, as danificações relativas às fissuras.

Em relação à velocidade de secagem, pode-se observar na Figura 3, para os diferentes fluxos de ar, o tempo necessário para as sementes atingirem umidade de $13 \%$, em diversas alturas da camada de sementes no silo. Verifica-se, no menor fluxo de ar, que os tempos necessários para alcançar as alturas de 0,50 e $1,50 \mathrm{~m}$ foram de $118 \mathrm{~h}$ e $182 \mathrm{~h}$, respectivamente. No maior fluxo de ar foram gastos, respectivamente, 70 e 102h. Assim, para atingir uma altura três vezes maior, foi necessário um tempo aproximadamente $50 \%$ maior, para os dois fluxos de ar considerados. Além disso, a redução do fluxo de ar de 20 para $5 \mathrm{~m}^{3} \cdot \mathrm{min}^{-1} \cdot \mathrm{t}^{-1}$ determinou aumento de $80 \%$ no tempo de secagem, para chegar na altura de 1,50m.

O fluxo de ar de $20 \mathrm{~m}^{3} \cdot \mathrm{min}^{-1} \cdot \mathrm{t}^{-1}$ apresentou, para a altura de $0,50 \mathrm{~m}$, velocidade de secagem (pontos percentuais de água removidos por hora de secagem) igual a 0,24 pontos 


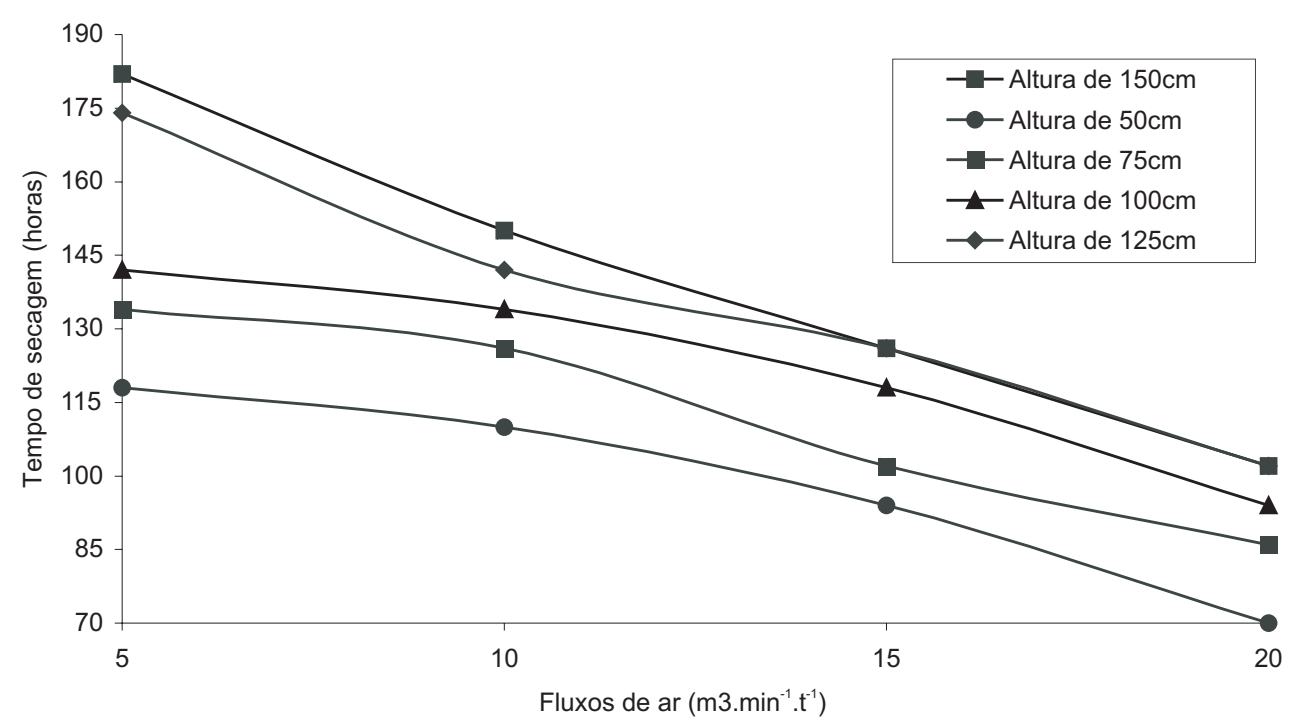

FIGURA3. Tempo de secagem conforme o fluxo de ar e a altura da camada de milho em espiga.

percentuais (pp) por hora e para 1,50m, de 0,16pp. $\mathrm{h}^{-1}$, enquanto que fluxo de ar de $5 \mathrm{~m}^{3} \cdot \mathrm{min}^{-1} \cdot \mathrm{t}^{-1}$, determinou uma velocidade média de secagem de 0,14 e 0,09pp. $\mathrm{h}^{-1}$, para as alturas de 0,50 e $1,50 \mathrm{~m}$, respectivamente. Romano Filha (1999) obteve velocidade de secagem três vezes maior, de $0,3 \mathrm{pp} \cdot \mathrm{h}^{-1}$, sob fluxo de ar de $5,5 \mathrm{~m}^{3} \cdot \mathrm{min}^{-1} \cdot \mathrm{t}^{-1}$, à temperatura de $45^{\circ} \mathrm{C}$, entretanto, ocasionou fissuras às sementes e determinou elevado gradiente de umidade entre as sementes localizadas em diferentes alturas do secador.

Para a secagem de uma camada de sementes de $1,50 \mathrm{~m}$, utilizando o fluxo de ar de $20 \mathrm{~m}^{3} \cdot \mathrm{min}^{-1} \cdot \mathrm{t}^{-1}$, foram requeridas 102 horas, ou seja, a velocidade média de avanço da frente de secagem foi de $0,38 \mathrm{~m} \cdot \mathrm{dia}^{-1}$, enquanto que o fluxo de ar de $5 \mathrm{~m}^{3} \cdot \mathrm{min}^{-1} \cdot \mathrm{t}^{-1}$, determinou velocidade média de $0,19 \mathrm{~m} \cdot \mathrm{dia}^{-1}$, mostrando que não houve proporcionalidade direta entre fluxo de ar e velocidade de avanço da frente de secagem.

A partir da camada de espigas de altura $0,50 \mathrm{~m}$, a velocidade de secagem começou a diferenciar-se conforme o fluxo de ar, de forma que, no mais alto fluxo de ar, no quarto dia, alcançou a altura da camada de milho em espiga de 1,50m, enquanto que nos fluxos de ar de 15,10 e $5 \mathrm{~m}^{3} \cdot \mathrm{min}^{-1} \cdot \mathrm{t}^{-1}$ alcançaram esta mesma altura no quinto, sexto e oitavo dia, respectivamente.

O comportamento da umidade das sementes de milho em espiga, em função da altura da camada de sementes, para cada fluxo de ar utilizado na secagem estacionária, particularizando o período de 62h é mostrado na Figura 4. Observa-se que, até $0,75 \mathrm{~m}$, os fluxos de ar de 5 e $10 \mathrm{~m}^{3} \cdot \mathrm{min}^{-1} \cdot \mathrm{t}^{-1}$ apresentaram comportamento semelhante. No entanto, a diferença entre as velocidades de secagem para cada fluxo de ar empregado, ocorreu em reduzida proporção, diferenciando-se praticamente de 1 a 3pp de água dentro de cada altura avaliada. De um modo geral, observou-se que a velocidade de secagem não foi proporcional ao aumento do fluxo de ar através da massa de sementes.

Verificou-se ainda que, na relação entre o grau de umidade e altura da camada, praticamente as alturas não influenciaram a velocidade de secagem (Figura 4). Entretanto, a influência exercida pelo fluxo de ar pode ser observada, sendo que o fluxo do ar de $20 \mathrm{~m}^{3} \cdot \mathrm{min}^{-1} \cdot \mathrm{t}^{-1}$ proporcionou mais rápida retirada de água da semente. Como foi visto anteriormente, o fluxo de ar mais alto requereu 70 horas para que a altura de $0,50 \mathrm{~m}$ atingisse grau de umidade de $13 \%$, enquanto que o mais baixo necessitou de 118 horas para atingir a mesma altura. Observou-se também que, mesmo a altura não tendo influenciado o avanço da frente de secagem, quanto menor a espessura da camada, menor o grau de umidade final das sementes (Tabela 1). Mesmo assim, a diferença de umidade entre as diferentes camadas foi, no máximo, de dois pontos percentuais. Nos menores fluxos de ar, a diferença alcançou 1,5pp entre o topo e a

TABELA1. Umidade final das sementes de milho em espiga, em função de fluxo de ar e altura de camada de espigas durante a secagem em silo.

\begin{tabular}{ccccccc}
\hline FLUXO DE AR & \multicolumn{6}{c}{ CAMADA DE SEMENTES $(\mathrm{m})$} \\
\cline { 2 - 6 }$\left(\mathrm{m}^{3} \cdot \mathrm{min}^{-1} \cdot \mathrm{t}^{-1}\right)$ & 0 & 0,50 & 0,75 & 1,00 & 1,25 & 1,50 \\
\hline 5 & 11,6 & 11,5 & 11,8 & 12,0 & 12,5 & 13,1 \\
10 & 11,5 & 11,5 & 12,0 & 12,3 & 13,0 & 13,0 \\
15 & 10,9 & 11,2 & 11,8 & 12,2 & 12,5 & 12,9 \\
20 & 11,0 & 11,0 & 11,5 & 12,0 & 12,6 & 13,0 \\
\hline
\end{tabular}


base da camada de sementes.

O processo de secagem ocorreu, nas diferentes camadas de espigas, de forma simultânea, de maneira que as sementes na altura de 1,50m, após 62 horas de secagem, já tinham reduzido o grau de umidade de 30 para $23 \%$ no menor fluxo de ar e de 30 para 21\% no maior fluxo de ar (Figura 4).

A qualidade fisiológica das sementes não apresentou efeitos prejudiciais até seis meses de armazenamento, independentemente do fluxo de ar e da altura da camada de sementes (Tabela 2). Os testes de germinação, envelhecimento acelerado, frio sem solo e emergência de plântulas em campo apresentaram valores superiores a 95\%, evidenciando a alta qualidade das sementes.

As avaliações da qualidade realizadas ao final de um ano de armazenamento, em condições ambientais, mostraram que,

TABELA 2. Qualidade fisiológica de sementes de milho em espiga, durante a secagem em silo, em função do tempo de armazenamento.

\begin{tabular}{ccccc}
\hline $\begin{array}{c}\text { Tempo } \\
(\text { meses })\end{array}$ & $\begin{array}{c}\text { Germinação } \\
(\%)\end{array}$ & $\begin{array}{c}\text { Envelhecimento } \\
\text { Acelerado }(\%)\end{array}$ & $\begin{array}{c}\text { Teste de } \\
\text { Frio }(\%)\end{array}$ & $\begin{array}{c}\text { Emergência em } \\
\text { Campo }(\%)\end{array}$ \\
\hline 0 & $97 \mathrm{a}$ & $96 \mathrm{a}$ & $96 \mathrm{a}$ & $97 \mathrm{a}$ \\
6 & $97 \mathrm{a}$ & $96 \mathrm{a}$ & $96 \mathrm{a}$ & $98 \mathrm{a}$ \\
12 & $95 \mathrm{a}$ & $94 \mathrm{a}$ & $80 \mathrm{~b}$ & $95 \mathrm{a}$ \\
\hline
\end{tabular}

Médias seguidas pela mesma letra na coluna não diferem entre si pelo teste de Duncan, em nível de probabilidade de $5 \%$ para o fluxo de ar de $20 \mathrm{~m}^{3} \cdot \mathrm{min}^{-1} \cdot \mathrm{t}^{-1}$, as sementes de milho apresentaram no teste de frio resultados superiores a $90 \%$, enquanto que, nos menores fluxos de ar, apresentaram resultados inferiores a $80 \%$ (Tabela 3). Este fato destaca a sensibilidade do teste de frio em detectar as alterações deteriorativas em sementes e ratifica as recomendações do uso deste teste de vigor para sementes de milho. Outro aspecto sobre a constatação do declínio da qualidade das sementes, em determinados tratamentos, é explicado pela espera de secagem quando as sementes estão úmidas, especialmente com umidade superior a $20 \%$, devendo por isso, serem secas o mais rápido possível, ocorrência apenas verificada com fluxo de ar de $20 \mathrm{~m}^{3} \cdot \mathrm{min}^{-1} \cdot \mathrm{t}^{-1}$.

TABELA3. Desempenho de sementes de milho pelo teste de frio, em relação ao fluxo de ar e ao período de armazenamento, após secagem em silo.

\begin{tabular}{cccc}
\hline \multirow{2}{*}{ Fluxos de $\operatorname{ar}\left(\mathrm{m}^{3} \cdot \min ^{-1} \mathrm{t}^{-1}\right)$} & \multicolumn{3}{c}{ Periodo de armazenamento (meses) } \\
\cline { 2 - 4 } & 0 & 6 & 12 \\
\hline 5 & $97 \mathrm{a}$ & $97 \mathrm{a}$ & $75 \mathrm{~b}$ \\
10 & $97 \mathrm{a}$ & $96 \mathrm{a}$ & $74 \mathrm{~b}$ \\
15 & $96 \mathrm{a}$ & $97 \mathrm{a}$ & $76 \mathrm{~b}$ \\
20 & $97 \mathrm{a}$ & $97 \mathrm{a}$ & $93 \mathrm{a}$ \\
\hline
\end{tabular}

Médias seguidas pela mesma letra na linha não diferem entre si pelo teste de Duncan, em nível de probabilidade de 5\%

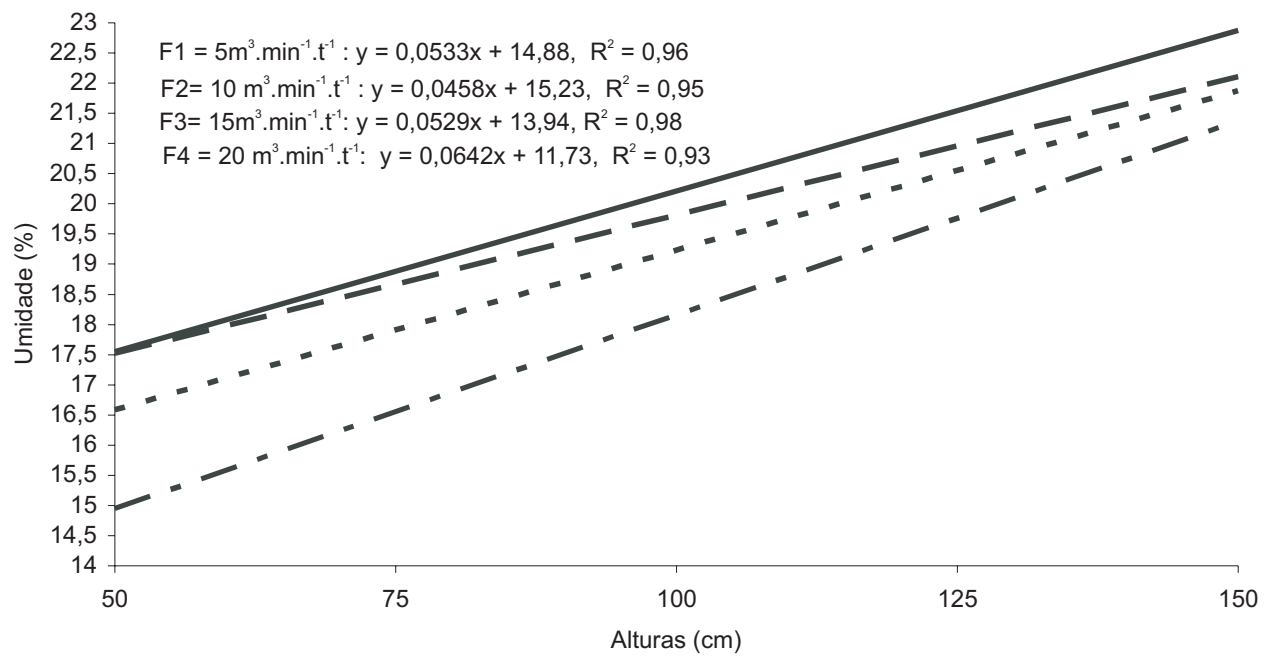

FIGURA 4. Comportamento da umidade das sementes de milho em espiga, após 62 horas de secagem em silo. 


\section{CONCLUSÕES}

A secagem estacionária de milho em espiga, utilizando ar com umidade relativa entre 40 e $70 \%$, não ocasiona fissuras às sementes de milho.

A velocidade mínima de secagem de milho em espiga, com grau de umidade superior a $25 \%$, deve ser de 0,2 pontos percentuais por hora.

O emprego de ar de secagem, com umidade relativa entre 40 e 70\%, determina um gradiente máximo de umidade de dois pontos percentuais ao final da secagem, em camada de 1,50m de sementes de milho em espiga.

A velocidade média de avanço da secagem de sementes de milho em espiga é afetada de forma não diretamente proporcional pelo fluxo de ar.

\section{REFERÊNCIAS}

BAUDET, L. Armazenamento de sementes. In: PESKE, S.T.; ROSENTHAL, M.; ROTA, G. (Ed.) Sementes: fundamentos científicos e tecnológicos. Pelotas: UFPel , 2003. p.370-416.

BAUDET, L.; VILLELA, F.; CAVARIANI, C. Princípios de secagem. Seed News, Pelotas, n.10, p.20-27, 1999.

BRASIL, Ministério da Agricultura e Reforma Agrária. Regras para análise de sementes. Brasília: SNDA/DNDV/CLAV, 1992. 365p.

CARVALHO, N.M. de. A secagem de sementes. Jaboticabal: FUNEP, 1994. 165p.

CHAI, J. Optimum moisture content of seeds stored at ambient temperatures. Seed Science Research, New York, v.1, n.8, p.2328, 1998.

GUNASEKARAN, S.; PAULSEN, M.R. Breakage resistance of corn as a function of drying rates. Transactions of the ASAE, St. Joseph, v.26, n.6, p. 2071-2076., 1985.

HERTER, U.; BURRIS, J.S. Changes in moisture, temperature, and quality of soybeans seed during high-temperature drying. Canadian Journal of Plant Science, Otawa, v.69, n.3, p.749-761, 1989.
HU, X.; ZHANG, Y.; HU, C.; TAO, M.; CHEN, S. A comparison of methods for drying seeds: vacuum freeze-drier versus silica gel. Seed Science Research, New York, v.1, n.8, p. 29-33, 1998.

LOEFFLER, N.L.; MEIER, J.L.; BURRIS, J.S. Compararison of two cold test procedure for use in maize drying studies. Seed Science and Technology, Zürich. v .13, n. 2, p.653-658, 1985.

MARCOS FILHO, J.; CÍCERO, S.M.; SILVA, W.R. Avaliação da qualidade de sementes. Piracicaba: FEALQ, 1987. 230p.

NAVRATIL, R.J.; BURRIS, J.S. Effects of high temperaturen drying on corn seed quality. Seed Science and Technology, Zürich. v.1, n.1, p.1-2, 1980 .

PESKE, S.T.; LILGE, C. Alta temperatura de secagem na qualidade de semente de milho (Zea mays L.). In: SALÃO DE INICIAÇÃO CIENTÍFICA, 10., FEIRA DE IC, 7., 1998, Porto Alegre. Anais... Porto Alegre: UFRGS. v.1,p.120.

POPINIGIS, F. Fisiologia de sementes. 2 ed. Brasília. AGIPLAN. 1985. 289p.

PETERSON , J.M.; PERDOMO, J.A.; BURRIS, J.S. Influence of kernel position, mechanical damage and controlled deterioration on estimates of hybrid maize seed quality. Seed Science of Technology, Zürich. v.23, n. 2, p.647-657, 1995.

QUEIROZ, D.M.; PEREIRA, J.A.M. Secagem à baixa temperatura. Viçosa: UFV/ CENTREINAR, 1987, 30p.

ROMANO FILHA, M.L. Alta temperatura de secagem na qualidade de sementes de milho (Zea mays L.). 1997. $26 f$. Dissertação (Mestrado em Ciência e Tecnologia de Sementes), Faculdade de Agronomia Eliseu Maciel, Universidade Federal de Pelotas, Pelotas, 1997.

SCARANARCI, C.: CICERO, S.M.; OLIVEIRA, P.R.P. Retardamento de secagem de espigas e qualidade de sementes de milho (Zea mays L.). Informativo ABRATES, Curitiba, v.7, n.1/ 2, p.50, 1997.

VILLELA, F.A; PESKE, S.T. Secagem de sementes. In : PESKE, S.; ROSENTHAL, M; ROTA G. (Ed.) Sementes: fundamentos científicos e tecnológicos. Pelotas: UFPel, 2003. p. 283-321.

WALTER, S.C.; ENGELS, J. The effect of storing seeds under extremily dry conditions. Seed Science Research, New York, v. 8, n.1, p. 3-8, 1998. Supplement.

ZONTA, E.P.; MACHADO, A.A. Sistema de análise estatística para microcomputadores - SANEST. Pelotas: UFPel, Instituto de Física e Matemática. 1984. 150p. 